\title{
THREE DIMENSIONAL ULTRASOUND WITH POWER DOPPLER STUDY OF CHANGES IN UTERINE FIBROIDS AFTER LAPAROSCOPIC UTERINE ARTERIES OCCLUSION
}

\author{
Mohamed Eltotongy*, Talal Amer**, Mohamed Abu Elata** \\ Department Obstetrics \& Gynecology*, Department of Diagnostic Radiology** \\ Mansoura University Hospitals, Faculty of Medicine, Mansoura University
}

\section{ABSTRACT}

Background: Uterine arteries occlusion either laparoscopically or radiologically has become an alternative to hysterectomy treatment of symptomatizing uterine myomas. Despite these methods proved to be effective modalities of treatment, yet its mechanism of improving the symptoms have not been clearly identified.

Objective: To assess the change of uterine and myoma volumes together with vascular change using 3Ds ultrasound with power Doppler after laparoscopic uterine arteries occlusion.

Study design : Prospective clinical study

Main outcome measures: The percentage reduction in the total uterine and myoma size, changes in the vasculature of the uterus and myomata and its correlation to the clinical response was evaluated.

Results: From 40 patients recruited in the study $36(90 \%)$ underwent technically successfull laparoscopic coagulation of the uterine vessels without intra operative complications. The main follow up time was 3,6,12 months. Symptomatic improvement occured in $88.9 \%$ and mass reduction in uterine and myoma volumes respectively was $64.6 \%$ and $78.8 \%$. Also, there was a significant difference between pre and post operative power doppler study uterine vascular assessment among improved patients.

Conclusion: Symptoms improvement occurs in laparoscopic uterine arteries occlusion is mainly correlated to changes in vascular supply to the uterus and myoma that lead to cell death or apoptosis which consequently reduces the myoma size and clinically improve the patient symptoms.

\section{INTRODUCTION}

Laparoscopic occlusion of the uterine arteries has become one of the patient and gynecologist preferred approach for he treatment of symptomatic uterine fibroid tumors (1).

Occlusions of the utcrine arteries which are the predominant source of blood flow to the fibroid tumours in most cases is the corner stone of treatment. Although it is becoming a widely accepted method as an alternative to hysterectomy treatment of the uterine fibroid lumour, great familiarity with the normal and variable pelvic arterial anatomy is needed to ensure the safety and success of the procedure ${ }^{(2)}$.

Angiography is used for comprehensive pretreatment assessment of pelvic arterial anatomy. For non-invasive evaluation; doppler ultrasonography, contrast matcrial enhanced magnetic resonance (MR) imaging and $\mathrm{MR}$ angiography may also be used. However, further information about tumour angiogenesis can be obtained by three- dimensional (3D) view of the vascular architecture. The continual change in color with direction and velocity, makes conventional 
colour Doppler difficult to obtain and evaluate ${ }^{(3)}$. But by using power mode, longer segment of vessels can be visualized continuously thus making vascular anatomy easier to track $^{(4)}$.

Uterine arteries occlusion was first introduced for managing the obstetrical hemorrhage by tansarterial embolization. After that, Rovina et al reported a successful outcome in treating symptomatic myoma by performing uterine artery embolization ${ }^{(5,6)}$; since then, up till now many studies reported uterine occlusion either laparoscopically or radiologically became an effective management of symptomatic myomata. Nevertheless, the exact mechanism by which this method reduces the patients symptoms have not been yet clearly identified; the suggestive mechanism is the change in the vascularity of the utcrine wall and myomata. Therefore; the purpose of this study was to clarify the degree and mechanism involved in the myoma size reduction and symptoms improvement through the study of changes of vascular network of the uterus and myomata before and after the laparoscopic uterine arteries occlusion using 3 dimensional ultrasound and power Doppler flow study ${ }^{(7)}$.

\section{MATERIALS \& METHODS}

Between January 2005 and December 2007 forty patients were enrolled in this prospective study; we recruited patients having uterine fibroids with symptoms including menorrhagia, dysmenorrhea and urinary frequency. The patients age was between 30-40 years (mean 38.19y) and warrant surgical treatment either hysterectomy or myomectomy and wanting to retain their uteri.

The preoperative evaluation of the gynecologist was done for all patients; the base line uterine and myoma size were measured by 3Ds ultrasound scan and their volumes were calculated also. Utcrine artery flow together with myoma vasculature were cvaluated using 2Ds power Doppler; all patients were counselled extensively regarding the potential risks. and benefits, the curative nature and the possible conversion to hysterectomy, myomectomy, or medical treatment .

All ultrasound measurements (pre-operative and post-operative) were performed using Sonoacc 8800) (Medison) using colored power Doppler in the 2D mode. Flow velocity wave forms were oblained from the ascending uterine arteries in longitudinal plane before entering the uterus and PI \& RI were also evaluated, then the ultrasound machine was switched to $3 \mathrm{D}$ mode, and the area of interest, uterinc fibroid was then acquired and stored for later analysis.

The built in VOCAL (virtual organ computer aided analysis) imaging program for the $3 \mathrm{D}$ volume calculation analysis was used with computer algorithms to form the fibroid volume and when umultiple myomas were seen, the volume of individual fibroids was added to give the total volume.

During the analysis and calculation, the manual mode of VOCAL was used to cover the whole 3D volume of the myoma with a 15 degree rotation step.

Uterine artery ligation under general anaesthesia was done, (3 puncture technique was used) after proper insufflations and proper visualization; both ureters were first identified and then the pelvic peritoneum overlying the uterine artery was dissceted through a lateral approach, then the uterine artery was grasped with atrumatic forr. 3 s and ligated with clips or coagulated with bipolas scragulation.

\section{Follow up}

All patients were infomed to record any perecived symptoms at 3,6 and 12 months following the procedure, and ultrasonography was done to measure 
the myomata volumes and its vascular change. Information regarding the clinical symptoms was obtained and the patients bleeding score charts were collected.

\section{Statistics}

The volumes of the uteri and myomas were obtained before and 3,6 and 12 months after laparoscopic procedure of uterine artery obstruction; the main value and standard deviations were also calculated. The paired t-test was used to evaluate the statistical difference and a p-value of less than 0.05 was considered to be statistically significant

\section{RESULTS}

As shown in table I out of 40 patients in the study, technical success occurred in 36 patients $(90 \%)$ while technical failure happened in 4 patients $(10 \%)$. The mean age of the studied group was $38.47 \pm 5.2$ years, menorrhagia was the main symptoms in $75 \%$ of the group, metrorrahagia was in $25 \%$ and $27.5 \%$ complained from pressure symptoms with bleeding problems. In the operated group, the symptoms improved in $88.9 \%$ of patients while 4 patient (11.1\%), had no improvement. 2 patients $(5.6 \%)$ had low grade fever for 48 hour after laparoscopy and 5 patients sufferred from pain also for 2 days after surgery. From the studied group, 35 patients had a solitary myoma and 5 patients had multiple myomata.

Change in the myoma size: The avarge sonographic uterine size (including the myomata) was $427.9 \mathrm{~cm}^{3}$ before the procedure and the myoma size $119.8 \mathrm{~cm}$ whereas these figures significantly decreased to $161.8 \mathrm{~cm}^{3}$ and $20.4 \mathrm{~cm}^{3}$ for the uterine size and myoma size respectively 3 months after the procedure was performed $(p=0.001)$. A further reduction in size was noted 6 and 12 months after the procedure with average mass reduction is $64.6 \%$ and 78.8 in uterine and myoma size respectively (Table II).

The vascularity by power Doppler after the procedure presented a change in 36 cases $(90 \%)$ that occurred in the improved patients and no change in the 4 patients who did not improve.

Table (I): Patient characteristics.

\begin{tabular}{|c|c|c|}
\hline Age & $30-45$ & $38-47 \pm 5191$ \\
\hline \multicolumn{3}{|l|}{ Symptoms } \\
\hline - Menorrhagia & 30 & $75 \%$ \\
\hline - Metrorrhagia & 10 & $25 \%$ \\
\hline - Pressure symptoms & 11 & $27 \%$ \\
\hline Symptom relieved & 32 & $88.9 \%$ \\
\hline No improvement & 4 & $11.1 \%$ \\
\hline \multicolumn{3}{|l|}{ Side effects } \\
\hline - Fever & 2 & $5.6 \%$ \\
\hline - Pain & 5 & $13.9 \%$ \\
\hline Technical success & 36 & $90 \%$ \\
\hline Technically failed & 4 & $10 \%$ \\
\hline \multicolumn{3}{|l|}{ No. of myomata } \\
\hline - Solitary & 35 & $87.5 \%$ \\
\hline - Multiple & 5 & $12.5 \%$ \\
\hline
\end{tabular}


Table (II): 3Ds Volume calculation of the uterus and myomas before and after LOUA.

\begin{tabular}{|l|c|c|c|c|c|}
\hline \multirow{2}{*}{ Item } & \multirow{2}{*}{ Preoperative } & \multicolumn{3}{|c|}{ Postoperative } & $\begin{array}{c}\text { Average } \\
\text { reduction } \\
\text { \% }\end{array}$ \\
\cline { 3 - 6 } & 3 months & 6 months & one year & $\begin{array}{c}\text { 6 } \\
\text { Uterine }\end{array}$ \\
Myoma size & $427.9 \mathrm{~cm}^{3}$ & $161.8 \mathrm{~cm}^{3}$ & $157.2 \mathrm{~cm}^{3}$ & $151.9 \mathrm{~cm}^{3}$ & $64.6 \mathrm{~cm}^{3}$ \\
$2119.8 \mathrm{~cm}^{3}$ & $20.9 \mathrm{~cm}^{3}$ & $27.09 \mathrm{~cm}^{3}$ & $25.2 \mathrm{~cm}^{3}$ & $78.8 \mathrm{~cm}^{3}$ \\
\hline
\end{tabular}

$P$ value $<0.001$

LOUA = laparoscopic occlusion of the uterine arteries

Table (III): Comparison of uterine and myoma vascular changes in the studied group measured by power Doppler flow indices.

\begin{tabular}{|l|c|c|c|}
\hline & \multirow{2}{*}{$\begin{array}{c}\text { Preoperative } \\
\text { No. 40 pt. }\end{array}$} & \multicolumn{2}{|c|}{ Post operative } \\
\cline { 3 - 4 } & & Clinically improved (36 pt.) & Clinically not improved (04 pt.) \\
\hline Average uterine PI & $1.94(1.1-3.02)$ & $2.01(1.3-3.9-3.9)$ & $1.55(1.2-3.0)$ \\
\hline Average uterine RI & $0.82(0.66-0.96)$ & $0.83(0.69-0.44)$ & $0.84(0.71-0.89)$ \\
\hline Myoma VI\% & $1.087(0.009-14.7)$ & 0.00 & 0.868 \\
\hline Myoma FI (0-100) & $23.566(0-36.29)$ & $0.055(0-0.1)$ & $22.436(0-29.839)$ \\
\hline Myoma VFI (0-100) & $0.241(0-4.40)$ & $0-0.004$ & $0.204(0-3.423)$ \\
\hline
\end{tabular}

PI: Pulsitility index - RI: Resistant index - VI: Volume index - FI: Flow indices

The average uterine PI and RI did not change from preoperative Doppler signal obtained from the uterine artery proximal to the obstruction, but the myoma power Doppler flow indices between the clinically improved women and those not improved, presented a significant change between preoperative and postoperative results.

\section{DISCUSSION}

Radiologic transarterial embolization was introduced in the late $1960 \mathrm{~s}$ to treat pelvic haemorrhage following trauma or radiotherapy ${ }^{(8)}$ and took the form of uterine artery embolization. In 1979 the technique used for hemostasis in postpartum haemorrhage ${ }^{(2)}$. Thereafter uterine artery embolization began to be used for postpartum and post hysterectomy bleedings. Considering the fact that laparoscopic techniques are often in the field of gynecologic surgery, laparoscopic uterine artery ligation is likely to attract considerable interest in gynecologic practice.

So uterine artery embolization and laparoscopic uterine artery ligation have become alternative treatment modalities for symptomatic fibroids rather than hysterectomy or myomectomy, yet no information regarding their mechanism and long term outcomes are availabe ${ }^{(\mathcal{(})}$.

Cell death consists of cell necrosis and apoptosis. Therefore, the death of leiomyoma cells following the obstruction of uterine blood flow could be caused by either necrosis or opoptosis (10).

Cell injury usually takes place during the process 
of hypoxia and reperfusion ${ }^{(11)}$. The degree of cell death depends not on the duration of hypoxia, but occurs during the reperfustion following acute hypoxia injury apoptosis mainly occurs under hypoxic but abrupt schamia induce cell necrosis ${ }^{(12)}$.

As shown in the present study, a significant reduction in the uterine size (64.6\%) and myoma size $(78.8 \%)$ is achieved after laparoscopic uterine artery obstruction which lasted for 1 year follow up with no recurrence. The current observation imply that myoma re-growth due to reperfusion or energy supplementation had not occurred after the procedure up to one year.

Power Doppler study proved to be an effective method for the study of the uterine and ovarian vasculature. Statistically significant difference in the vasculairty of myomata before and after the uterine artery obstruction among the clinically improved patients while no significant difference occurred in those who presented no improvement. So, a sudden change in the angiogenesis of the myoma after the laparoscopic procedure appear to be the initiating effect in cell death and apoptosis that reduce the myoma size and improve the bleeding symptoms. However, the question remains as to when the collateral flow via the ovarian arteries may develop and when it does, will it ignificantly contribute to myoma re-growth and resumption of its troubles. These necessitate further studies with a longer follow up period and larger study population.

\section{REFERENCES}

1. Z Holub A Jabor L, Kliment: The role of laparoscopic dissection of the uterine artery in the surgical treatment of fibroid related menorrhagia: a pilot study Gyneoclogyical surgery 2004; 1,3 pp 183-187.
2. Jean Pierre $\mathrm{PL}_{\mathrm{L}} \mathrm{I}$ aye et al: Uterine froroid vasculrization and clinical relevance to uterine fibroid embolization radiographic 2005; 25; s99-s117.

3. Kurjak A., Kupesic. Urek S and Marc D.: The assessment of benign uterine tumour vasculaization by transvaginal color Doppler ultrasound med boil $1992 ; 18,645-649$.

4. Kupesic S, Bekavac I, Bjelos D and Kujak A: Assessment of endometrial receptivity by transvaginal color Doppler and three dimensional power Doppler ultrasonography in patient undergoing invitro fertilization procedures $\mathrm{J}$ ultrasound Med. 2001; 20, 125-134.

5. Ravina JH, Bouret JM, Fried D: Value of preoperative embolization of uterine fibroma: report of a multicenter seies of 31 cases. Contracpt Fertile Sex. 1995; 23: 45-9.

6. Ravina JH, Bouret JM, Ciraru VN.: Recourse to particular arterieal emoblization in the treatment of some uterine leiomyoma. Bull Acd Natl Med. 1997; 181:233-243.

7. Ng EHY Chan CCEV, Tony OS, Yag WS Baad, HOPC: Endometrial and subednometrial blood flow measured during early luteal phase by three dimensional power Doppler ultrasound in excessive ovarian responders. Hum Repro. 2004; 19, 924-913.

8. Dee EF Fibroids: basic information In Eric JB Maclin VM, Editors, Malden: Blackwell Science 1998; P $1-14$.

9. Mclucas B, goodwin SC, Kaminsky D.: The embolized fibroid uterus. Minim invasive there allied technol 1998; 7: 267-271.

10. Lin WM: Laparoscopic Bipolar Coagulation of uterine vessels to treat symptomatic leiomyomas $\mathrm{J}$ Am Assoc Gynccol Laparose 2000; 7: 125-129.

11. Orsini L, Salardi S, Pilu G, Bovicelli L, Cacciari E.: 
Pelvic organs in permenarch-eal girsl: real time ultrasonography. Radiology 1984; 153: 113-116.

12. Rita H, Juha T, Ursula T, Sei A G, Aarre K, Erikki
$\mathrm{K}$, et al.: Combined laboratory and diary method for objective assessment of menstrual blood loss. Acta Obstet Gynecol Scan 1998; 77: 201-204. 